\title{
1
}

\section{Introduction: A Multilevel Perspective on Family Policy}

\author{
Rense Nieuwenhuis and Wim Van Lancker
}

What do the United Nations, the nation-state, a big city, and your local supermarket have in common? They all craft policies for families. At each of these levels of governance, family policies are formulated, voted for, implemented, and carried out-or not. And it is this whole set of multilevel policies that ultimately affect families' and individuals' choices, opportunities, constraints, and capability in terms of work, care, and well-being.

Of course, it is not simply a matter of trickle-down politics, with the highest level deciding and the other level following suit. There is constant interaction, exchange of norms and ideas, and policy feedback and learning between levels. The story of family policies and their outcomes can be read in many different ways, from bottom-up to top-down, from horizontal to vertical. Still, it is not the supermarket that designs family policies to be carried out at higher levels nor does the supermarket's company regulations affect many people outside of their shop. In contrast, Directives by the European Commission do affect all European citizens, at least in principle, and limit the scope of decision making for national politicians. For that reason, we begin our story at the top tier of governance, and throughout the book we

\footnotetext{
R. Nieuwenhuis ( $\square)$

Swedish Institute for Social Research (SOFI), Stockholm University, Stockholm, Sweden

e-mail: rense.nieuwenhuis@sofi.su.se

W. Van Lancker

Centre for Sociological Research, University of Leuven, Leuven, Belgium e-mail: wim.vanlancker@kuleuven.be 
descend over national and subnational policies to the local and company-level policies.

It is often overlooked that family policies are formulated and implemented at very different levels, that range from supranational (and international) organizations such as the United Nations (UN), the Organisation for Economic Co-operation and Development (OECD), and the European Union (EU), national or federal policies and legislation, the subnational municipalities, states, or regions in which people live, and finally the organizations in which people work. The historical dominance of the nation-state means that the heavy lifting in terms of policymaking is still carried out at that level. As a result, the academic literature on family policies at the national level is developed most extensively. Still, in recent years separate strands of the literature emerged in which each policy level has been studied separately, ignoring possible synergies and discrepancies between these different levels at which family policies are formulated and implemented.

Family policies have had a long-standing and profound impact on how families live their lives, how they are formed, and even what is considered to be a 'family.' The area of family policy constitutes a broad range of legislation and policies, that set out to achieve goals that include poverty alleviation, compensation for the economic costs of children, fostering employment, improve gender equality, support early childhood development, and raise birth rates (Thévenon, 2011). Although often not considered in analyses of 'family policy,' policies that relate to reproductive rights extend to policies on contraceptives, and induced abortion (Levels, Need, Nieuwenhuis, Sluiter, \& Ultee, 2012). Family policies were understood early on as an important nexus between family and the state (Gauthier, 1996). Not surprisingly, the literature on family policy outcomes blossomed, producing important concepts and insights on how individuals interact with the organizational and institutional context shaped by family policies, inspired by a variety of disciplines (Van der Lippe \& Van Dijk, 2001). While the literature on family policy used to be Western-centric, we now witness a true globalization of both the development of family policy and academic research on the issue (Robila, 2012).

Today, several societal developments point toward an increased importance of examining family policy at different levels. Organizations, often employers, offer attractive work(-family) arrangements in the competition for talented workers, and compensate to some extent for the absence of national-level policies (Den Dulk, Peters, \& Poutsma, 2012). At the same time, they are increasingly forced by national legislation to allow workers to request flexible working hours. Federal states have faced pressures to decentralize family 
policies or added new layers of governance, giving room to ideological differences to shape regional policy differences (Béland \& Lecours, 2005), which is clearly illustrated in the United States where states or even large cities such as New York have implemented family leave arrangements (Boushey, 2016). Urbanization and associated population decline in rural areas is associated with regional differences in the availability of public services. National policymakers are facing persisting gender and economic inequality, family diversity, and other so-called new social risks, budget deficits, and a seemingly constant concern about economic growth. Increasingly, supranational organizations issue recommendations or directives to which other policymakers have to relate. Examples include recommendations by the OECD, nations committing to the Beijing Platform for Action by the UN, and the 'Directive on work-life balance for parents and carers' adopted by the European Commission.

Addressing the disconnect between the academic literatures on different levels of governance with respect to family policies and their outcomes is one of the key aims of this Handbook.

\section{Purpose and Contribution of This Handbook}

The purpose and main contribution of this handbook is to provide a multilevel view on family policy outcomes, thus, as described in the previous section, combining insights on family outcomes at levels ranging from the potential impact of supranational organizations, via national policies, subnational/regional, and finally organizations or employers. Although the focus is on outcomes, at each of these levels some of the chapters also address (factors behind) the development of family policies.

The handbook seeks to make three additional contributions. The handbook will both take stock of existing theories and empirical research, as well as develop an agenda for the next decade of research on family policy outcomes. To that end, at each of the four levels discussed above, chapters are included that examine key concepts, summarize lessons learned, and focus on the frontiers of the research agenda.

Next, the handbook will be sensitive to heterogeneous policy impacts. As the literature on the outcomes of family policies burgeoned, it became increasingly clear that individuals and organizations react to family policies in heterogeneous ways. Family policy sits at the intersection between parenthood, family and employment, and taking due account of heterogeneity of parents in terms of preferences, family structure, class, opportunities 
and constraints in relation to decisions about care and employment, helps understand the outcomes of these policies more accurately (Mandel, 2012).

The final contribution of this handbook-inherent to its multilevel structure-is to bring together contributions from various academic communities that have operated with some degree of separation from each other. Such wide-ranging overview is not yet available and will combine academic literature that is well-developed (such as the organization level and the national level) to literatures that are rapidly gaining more prominence (such as the subnational/regional and supranational levels). Bringing together various academic communities in a comprehensive handbook fosters learning interdisciplinary lessons, cross-cutting across disciplines that include (but are not limited to) sociology, political science, business administration, demography, and economics.

\section{Outline of the Book}

As part of the introduction to this Handbook, Mary Daly (Chapter 2) sets out the framework of what constitutes 'family policies,' how they are changing, and how family policy should be theorized and studied going forward. The chapter provides the conceptual foundation on which the other chapters in this volume build, and provides the starting point for many of the empirical, conceptual, and theoretical discussions that will be tackled more in detail in particular chapters throughout. Daly's overall aim is to set out the constituent elements of family policy and explore the significance of family policy, especially in a context of socioeconomic, demographic, and political change. Focusing on long-standing welfare states, the first part of the chapter considers the functions of family policy, outlining both the classic aims and objectives and those found in more recent family policy. The different instruments of family policy are identified, including cash and tax payments, services, and leaves. These three mainstays of family policies are the focus of many of the subsequent chapters in this volume. In all of this, variation is emphasized and examined. In its second part, the chapter links changes and debates to the complex issues animated by family policy, such as questions about personal and national values, intergenerational balance and equity, gender equality and the differential politicization of aspects of individual and family life. Daly concludes that the agency of family policy change operates at different levels of policymaking. It is to these levels that we now turn. 


\section{Supranational}

The attention for the role played by supranational organizations and governing bodies such as the European Commission, the Organisation for Economic Co-operation and Development (OECD), the World Bank (WB), the International Labour Organisation (ILO), and the United Nations (UN) in the making of family policies has long been somewhat underwhelming. Yet, these organizations have a long history of influencing national policies, setting minimum standards, and adopting binding decrees or directives. For instance, the European Commission is increasingly involved in social outcomes and policies, including family policies, of European Union member states. This is quite clear in the development from the Lisbon agreements, over the social investment package to most recently the launching of the 'European Pillar of Social Rights.' As part of the latter, the European Commission issued a 'Work-Life Balance directive' in April 2017, with proposals that pertain to paternity leave, parental leave, carers' leave, and flexible working. This was adopted by the European Parliament in May 2019. Even more global, as early as 1919, the International Labour Organisation (ILO) influenced policymaking at lower tiers of governance through what Kahn and Kamerman (1978) termed 'implicit family policies,' policy domains and decisions that have consequences for families with children. In this case, a concern for equal treatment of men and women in the workplace and occupational health led to the adoption of a convention that obliged countries to put flesh to the bone of their family policies across the globe.

To fully capture the importance of the supranational level of governance in understanding the outcomes of family policies, this section starts with a chapter by Jane Jenson (Chapter 3) in which she charts the intellectual history of how international organizations (IOs) began to expand their areas of competence and intervention in the realm of family policy by proposing new policy directions in the name of sustaining employment, fighting poverty, social investment, or social development. Many of these touched directlyand even more indirectly - on policy fields that have long been part of the domain of family policy. Of course, exerting influence on policymaking at national, subnational, and company levels is not a one-way street, but it is the result of a complex exchange of ideas, influence, and power. The chapter explores these exchanges both horizontally across IOs and vertically across policy tiers (bottom-up as well as top-down). In the end, it seems that the three mainstays of family policy identified in this handbook were regularly underexposed because the policy frames shifted toward children or workers, stripping individuals from the family they are living in. 
Moreover, it is not because IOs of supranational bodies exert influence on norms and ideas or launch binding directives, that these are always fully transformed into actual policymaking at the national or lower policy levels. In her chapter, Linda White (Chapter 4) argues that some countries or national governments may regard the authority of IOs with suspicion or may regard IO endorsement as a reason not to adopt a policy domestically. Thus, even if policy ideas or norms become dominant at the international level, there can be varying levels of receptivity to those ideas within domestic policy processes. The chapter examines international norms on gender equality and human rights in general and family policies in particular, and shows that even if IOs may not directly affect decision making, they can facilitate the spread of ideas of best practices among member countries through their reports and conferences. Yet, White shows for liberal welfare states (Australia, Canada, New Zealand, UK, USA) that international norms are diffusing to domestic policy processes rather unevenly, particularly in countries in which decision making on family policies is decentralized. As such, IOs are still less authoritative than the national level when it comes to on-the-ground policymaking.

Interestingly, though, IOs are usually not monoliths but often comprise different agencies, secretariats, offices, and administrations within the overarching organization. In her chapter, Shahra Razavi (Chapter 5) provides a comprehensive overview of how three agencies within the United Nations (UN) look at family policy through different lenses, shaped by their different mandates and objectives, institutional context, intellectual history, and administrative capacities. These perspectives can be conflicting or not in sync with one another. With its focus on labor standards and decent work, the International Labour Organisation (ILO) had an important impact on families through norm-setting mechanisms and procedures, for instance through its conventions on maternity protection. At the same time, its focus on women as workers overlooks gender stereotypes and the role of men in family life. In a similar vein does UN Women impact family life, centering on key feminist concerns such as domestic violence and reproductive rights. UNICEF, then, sees families through the lens of children's rights, which tends to confine women to maternal roles, responsible for breastfeeding and ensuring children's nutritional needs. This unavoidably leaves out the needs of working parents, in particular mothers who do the bulk of unpaid care. At the same time, advocacy work on children's well-being has a tangible impact on women's rights and gender equality.

As becomes clear throughout the chapter, family policy sensu stricto is usually not front and center in these agencies' ideas and norms, but their 
actions do shape family life on a global scale. Although there is pathdependency in how different UN agencies approach family policy, there is also learning and changing of position. This is exemplified by a recent turn to family-friendly policies, connecting children's rights to women's rights and feminist concerns. It is still an open question whether these changes at the ideational level will fully translate into the programmatic level.

In any case, to fully understand how the supranational policy level and IOs shape family policies around the globe, one not only has to take due account of differences between IOs, their objectives and institutional makeup, but also within IOs. Just as there is no 'one UN' approach, as highlighted by Razavi, there is no 'one IO' approach or strategy to affect family policy to date.

\section{National}

At the national level, few countries had implemented a coherent set of family policies up until the 1980s. From that point on, however, state support for families expanded strongly across OECD countries. As a corollary, the study of national family policies became a rapidly expanding academic field, producing important insights on how individuals interact with the institutional context shaped by family policies drawing on qualitative as well as quantitative methods, inspired by a variety of disciplines (Van der Lippe \& Van Dijk, 2002). Alfred Kahn and Sheila Kamerman (1978) provided one of the first attempts at developing a comparative framework to study family policies. Since then, several studies showed how spending on national family policies increased strongly over time and how more employmentrelated forms of family policy such as childcare services and leave schemes developed alongside traditional cash components such as marriage subsidies and family benefits. Importantly, a key insight from the literature is that family policies do not emerge in a political vacuum but that they are path dependent and tied to dominant norms on gender and motherhood, and that they interact with and emerge in the context of broader welfare state arrangements (Gauthier, 2002; Montanari, 2000; Thévenon, 2011).

By drawing on specific conceptual and analytical frameworks, scholarship on family policies played an important role in understanding family policy outcomes and its variation across countries. In particular, the study of national family policies is strongly connected to the inclusion of gender in welfare state research. A famous example was the introduction of the concept of 'defamilization' (Lister, 1994; McLaughlin \& Glendinning, 1994) 
to counterbalance the central role played by 'decommodification' in EspingAndersen's (1990) influential welfare state typology—and to bring in a focus on gender and family and care relations. Decommodification is the degree to which individuals are able to uphold an acceptable standard of living independent of employment. In other words, if one does not work, how well is one protected by the welfare state? Yet, when the male breadwinner model is dominant and women's roles in providing unpaid care are subordinated to men's paid employment, such an approach of classifying welfare states and understanding its outcomes tends to be 'gender blind.' In response, Lister (1994) suggested the concept of familism (and the corresponding defamilization function of the welfare state) to better reflect how institutional arrangements cater to people engaging in care for children or relatives. Defamilization, then, is the degree to which individuals can uphold an acceptable standard of living independent of care relations within the family. The concept of defamilization subsequently was used to understand the outcomes of welfare states, a forteriori family policies, and how it affects individual's behavior in terms of care and employment given the gendered relations in terms of work and care within the family (Korpi, 2000; Lewis, 1992; Orloff, 2009). Policies enabling defamilization, such as paid parental leave and public provision of childcare, are instrumental in supporting women's labor force participation (Thévenon \& Luci, 2012). As such, the study of family policy is directly linked to the study of gender in relation to the state, the labor market, and the family.

Two chapters in this Handbook chart key concepts and theoretical approaches used in the analysis of national-level family policies. Hannah Zagel and Henning Lohmann (Chapter 6) provide a systematic and thorough discussion of the theoretical concepts used in comparative family policy, gender, and welfare state research. Besides providing an overview of the state of play of the theoretical ideas in this research area, they propose six criteria for evaluating and properly understanding family policy concepts. Such a multifaceted approach toward the conceptualization of family policies helps understand how and why family policies shape the lives of families. Zagel and Lohmann argue that a systematic discussion of the value and meaning of concepts used in the area of family policy research is crucial, since there are many similarities in the underlying ideas of concepts but also important differences which have mainly gone unnoticed. One prime example is the concept of defamilization which we have used ourselves in the previous paragraph. Several versions of the concept are used in the literature, usually without paying due attention to the history of the concept or the subtle differences in the interpretations of different varieties of the concept. So, 
gaining thorough understanding of the outcomes of family policies starts with gaining better understanding of the concepts underlying such research.

In the next chapter, Jana Javornik and Mara Yerkes (Chapter 7) take the multifaceted approach to understanding family policies even further. They argue that translating concepts into measurable indicators of family policies remains a conceptual and analytical challenge. Drawing on examples of British and Swedish policies on childcare, they discuss the difficulties involved in conceptualizing family policies in a cross-country comparative perspective and propose using the Capabilities Approach (CA) as a way forward. They demonstrate that the CA helps capture the complexity of analyzing family policies and their outcomes in a meaningful way, in particular by shifting focus to what extent family policies actually allow families, and women, in particular, to make meaningful choices within varying contexts. Applying the CA helps to evaluate family policies in a broader perspective than is usually done.

It is important to recognize that family policies are developed and implemented in the pursuit of attaining certain objectives. Those objectives are usually tied to a particular time, place, and context. Childcare, for instance, is a mainstay of modern family policies, receiving ample political, administrative, and academic attention. In Chapter 8, Michel Vandenbroeck dissects where this attention originated and provides a brief history of the development of childcare policies, or more broadly Early Childhood Education and Care (ECEC) policies, in a diverse set of countries. The chapter shows how childcare policy evolved from its nineteenth-century objective of providing custodial care for poor, working-class children to a twenty-first century objective of improving cognitive and noncognitive abilities of all children (Kamerman, 2006). To this end, improving quality and accessibility for all families became important policy goals. At the same time, as is also demonstrated elsewhere in this book, policies shape different opportunities for families at different intersections of inequality: disadvantaged children who would benefit most from high-quality childcare are usually the ones left out (Van Lancker \& Ghysels, 2016). Vandenbroeck argues that policies successful in equalizing access to high-quality childcare are policies that consider childcare as a public good rather than a marketized commodity, and polices that are built on the notion of proportionate universalism in which universal policies are combined with targeted actions toward disadvantaged families. In the majority of countries, however, this will require substantial investments in both quantity and quality.

The empirical literature on the outcomes of national family policy is well-developed since Kamerman and Kahn's pioneering work. In Chapter 9, 
Willem Adema, Chris Clarke, and Olivier Thévenon take on the challenge of summarizing such a vast field and provide an overview of research findings. They present an overview of the changes in family and work behavior and highlight the diversification of family models. Importantly, similar to Vandenbroeck, they point at growing inequalities associated with these changes. The chapter also looks forward by identifying important challenges ahead, such as the growing number of singles and single-parent families, the diversification of family forms, and growing inequalities between families. Recent developments in family policy are aimed largely at helping parents to balance work and family commitments and reducing gender inequality, including the provision of ECEC services, fathers-only paid parental leave and support for flexible working at different levels of governance, all three themes which are developed further in the subsequent chapters.

By now, it is clear that the vast majority of scholarly work in the field focuses on OECD and EU countries. Yet, it is important to emphasize the importance of studying family policy developments in other parts of the world as well, which enables to test the aforementioned concepts, classifications, and methods outside of the traditional Western-centrist 'worlds of welfare.' That is the purpose of the chapter by Fernando Filgueira and Cecilia Rossel (Chapter 10). They discuss country experiences across the globe in developing systems of family allowances, leave schemes, and childcare services. A comparison with the European and OECD countries shows that the majority of these countries have a long road ahead in growing a seed of family policies into a strong foundation of the welfare state. In many developing economies, family policies were established relatively recently and usually carry little weight in the total fiscal effort of these countries. And while some countries have seemingly generous leave policies in place, offering for instance full wage replacement rates, this is merely a paper reality. Most workers don't actually qualify for these policies. At the same time, however, the breadth and depth of family policies are growing in the majority of countries across the globe. In that respect, it is illuminating to see that in many of these countries the policy blueprint resembles the one in European welfare states albeit often with a particular path-dependent twist. This demonstrates that the conceptual and analytical framework applied in the literature to understand the outcomes of family policy bears broader relevance.

Let us now return to the issue of inequality. While earlier attempts at quantifying the outcomes of family policies and the effects of these policies on families' work and care behavior focused on the 'average family,' more recent studies acknowledge the heterogeneity of policy impacts and the existence of unintended consequences of 'deliberate policy action' (Merton, 1936). 
For instance, the use of formal childcare was found to be socially unequal, biased toward higher educated mothers, leading to the observation that the 'Matthew effect' prevailed in family policies (Pavolini \& Van Lancker, 2018). Trade-offs were found (Pettit \& Hook, 2009), with for instance provisions for part-time work and childcare services increasing the number of employed women while at the same time increasing gender inequality in wages. The provision of leave was found to be an indispensable measure to facilitate care and employment in motherhood while at the same time very long periods of leave were found to be a mechanism of exclusion of women from the labor market (Nieuwenhuis, Need, \& Van Der Kolk, 2017). Moreover, research showed that family policies have the potential to particularly benefit specific groups, such as children (Bradshaw \& Finch, 2002), the lower classes and the lower educated (Korpi, Ferrarini, \& Englund, 2013), large families and single parents (Nieuwenhuis \& Maldonado, 2018), in turn contributing to lower poverty rates and higher levels of well-being (Engster \& Stensöta 2011; Van Lancker \& Van Mechelen, 2015).

Several chapters explicitly take this heterogeneity in family policy outcomes into account. Jennifer Hook and Meiying Li (Chapter 11) examine trade-offs, interactions, and unintended consequences of the impact of family policies, parental leave, and childcare services in particular, on women's labor market outcomes. They present a concise overview of what they refer to as the 'uneasy consensus' that emerges from the literature on the effects of publicly funded childcare and parental leave on employment outcomes: both measures are considered to be supportive for women's employment. At the same time, this uneasy consensus falls apart once the heterogeneity of policy effects by social class is considered. They argue that a clear gap in the current state of the literature is our limited understanding of heterogeneity in policy effects as well as how inequality more broadly affects the relationship between family policy and women's employment. Childcare and parental leave policies are sometimes only to the benefit of middle- and upper-class women, while gains in terms of inclusion on the labor market can be offset by increasing inequalities between men and women in the labor market. To evaluate whether family policies attain their intended objectives, it is of utmost importance to be aware of trade-offs and heterogeneities. But studies come to contrasting conclusions, and there is still no consensus on the actual impact of educational level, or contextual factors such as labor market institutions, or cultural norms, on the outcomes of family policies. Hook and Li thus argue that our current conclusions in this area are based on, and they put it mildly, less than ideal policy data. How data limitations impede further progress in the field 
of family policy research is a key issue that is discussed throughout the book, in particular in Chapter 24.

Christine Skinner and Mia Hakovirta (Chapter 12), explore the current policy designs and principles pertaining to child support. There is a long policy history in most Western countries, but child support policies and separated families make unhappy bedfellows. The institutional and operational challenges are considerable as policies try to keep pace with changes in intimate family relationships, changes in household structures and changes in gendered patterns of employment. For example, to provide accurate determinations of child support, policymakers must track the procreation activities, living arrangements, and employment patterns of parents. It therefore matters whether parents go on to establish new partnerships and have more children. It also matters for children entitled to child support, who they live with and how the patterns of parental shared care are agreed upon. Given that the lifetime of a child support case could last for the duration of an individual's childhood (possibly as long as 18-21 years), the propensity for complexity is inherent within the policy design and principles. And it shows in the results. Skinner and Hakovirta demonstrate on the basis of a new expertbased dataset that a change toward greater gender equality in the division of labor in families is not reflected very much in child support systems over the last decade. They too point to heterogeneity in policy effects and trade-offs, in that the growing recognition of gender equality in child support systems might potentially jeopardize the poverty-reducing effects of those systems.

Further exploring the issue of changes in household structures and how policies cope, Laurie C. Maldonado and Rense Nieuwenhuis (Chapter 13) examine both the intended and unintended consequences of family policies for single-parent families. They analyze how national family policies support the specific group of single parents, addressing in particular how family policy interacts with their resources and employment. In doing so, they examine how redistributive and financial support policies not only operate differently than work-family reconciliation policies but also have a different impact for single parents in comparison with couples.

While most national family policies are geared toward families with children, the issue of care is obviously not limited to parents caring for children alone. As such, policies facilitating employment or care, and policies protecting against financial hardship while providing care, bear broader relevance for families in which children care for their parents. Pearl Dykstra and Maja Djundeva (Chapter 14) consider cross-national differences in European national policies regarding caring responsibilities for older family members. 
They argue that it is unfortunate that care policies are separated-conceptually as well as in practice-in 'young' and 'old' sections, because such separation overlooks interdependencies across generations and only provides a fragmented notion of what families are about. As such, they broaden the notion of family policies and consider questions such as the public provision of services for frail older adults, pension credits, and cash for care schemes. The chapter differentiates between policies that free family members from caring responsibilities and policies that enable them to care for older generations. The chapter shows that long-term care systems across Europe showed 'limited convergence' (Ranci \& Pavolini, 2013, p. 312): while universalistic systems retrenched their provisions, most of the residual care regimes expanded theirs. Throughout Europe, there has been a trend toward refamilialization of care, that is, shifting responsibility for long-term care from the state to individuals and their families. The chapter furthermore brings intergenerational relationships into the framework of heterogeneous policy impacts.

No matter how encompassing the literature on national family policies has become, many issues and challenges are still not well understood. Exciting new pathways are currently being explored, with for instance researchers focusing on understudied groups. Alzbeta Bartova and Renske Keizer (Chapter 15) focus on fatherhood, in search of support for the dual-carer family model. Starting from the observation that there is much heterogeneity in the care roles fathers adopt, their chapter explores family policies that have a potential to promote the dual-carer family model across 13 European countries. They find that although all countries offer fathers an individual nontransferable entitlement to child-related leave, in general, these policies do not sufficiently challenge the gendered distribution of paid and unpaid work. Since highly educated fathers and fathers with higher income are more likely to devote their time to childcare compared to their counterparts with lower educational attainment and income, Bartova and Keizer examine to what extent these policies help fathers with a different socioeconomic background to take up more childcare responsibilities. This, in turn and in combination with the relatively new EU Directive on Work-Life Balance for parents and carers, will presumably lead to more gender equality.

Marie Evertsson, Eva Jaspers, and Ylva Moberg (Chapter 16) introduce the concept of parentalization, defined as the ability to become a parent and be recognized as such, both legally and via social policies. In two parts, they examine who can become a parent and how, and who can share in the care of the child. Empirically, this chapter uses register data to show trends in the number of children with same-sex female and same-sex male parents, and 
how family leave policies apply to same-sex couples in the four largest Nordic countries and the Netherlands. These European countries were in the forefront of legally recognizing same-sex marriage and parenthood. This is a clear research frontier, since same-sex couples face greater difficulties being legally recognized as parents and to share the leave between them. This is important, not least as parental leave rights are key to long-term shared parenting and care, enabling a more equal division of leave for those who so desire.

\section{Subnational}

The chapters in this section focus on family policies that are formulated or implemented at the subnational level, for instance the level of the state, province, or municipality. Examining regional variation at these levels seems increasingly important in the light of ongoing decentralization. More generally, family policy provisions at the national level may not always be indicative of what citizens in different parts of the country can expect. For instance, although the United States is often described as one of the very few countries in the world that has no federal legislation on paid parental leave (Heyman $\&$ Earle, 2009), states and cities are implementing family policies at a rapid pace (Boushey, 2016).

Indeed, in many cross-national policy analyses, the United States is conceptually understood as the ideal-typical liberal regime that offers marketbased solutions to social problems, including work-life balance issues. Fittingly, the country lags behind most others in the world with respect to family policy generosity. However, there is considerable subnational variation that cross-national comparative research often overlooks. Therefore, in Chapter 17, Cassandra Engeman addresses how family leave policies developed across US states over time. Drawing on state legislative documents, the chapter identifies the dimensions on which state policies typically vary. The chapter shows how state policies generally shifted from maternity leave to gender-neutral family leave to paid leave schemes, characterizing some states as more innovative than others. Comparing leave policy development in the United States to other countries, the chapter highlights often overlooked, innovative aspects of US family policy, most notably, the emphasis on individual entitlements to leave rights and the distinction between leave for health and caregiving needs that are gender-neutral in purpose. The chapter thus presents subnational variation in family policy as a rich area for future research and demonstrates that cross-national comparative research on family policy outcomes should consider subnational variation when including 
federal systems, such as the United States, in the analysis. Taking stock of evidence of increasing subnational divergence throughout the past two decades, Zachary Parolin and Rosa Daiger von Gleichen (Chapter 18) investigate the extent to which a family's ability to achieve financial recourse from the welfare state and/or market varies across the 50 United States. The findings demonstrate that states' family policy packages vary widely with respect to the generosity and accessibility of social assistance, health insurance, net incomes from minimum wage employment, publicly supported childcare and pre-K, and paid family leaves. Moreover, the chapter investigates the extent to which this cross-state variation in family policies helps to explain differences in family employment and poverty outcomes across the United States. The findings indicate that states became more similar in the amount of benefits received from the federally funded Supplemental Nutrition Assistance Program (SNAP), Supplemental Social Security Income (SSI), and the Earned Income Tax Credit (EITC), but less similar in terms of benefits received from Temporary Assistance for Needy Families (TANF). Moreover, divergence in policies has not always translated into divergence in social outcomes.

Drawing on the case of Germany, Pia Schober (Chapter 19) argues that considering different levels of regional and local variations within a county offers great potential for generating new insights on mechanisms of how family policies affect families' practices and choices. The chapter first describes the institutional context of childcare provision in Germany and the existing variation in regional provision and take-up of services. It then reviews different theoretical perspectives on potential drivers of policy variations at the municipality and federal state level and connects these to existing empirical evidence. The second part of the chapter proposes a framework for investigating socially stratified parental work-care choices at subnational levels by connecting a macro-micro rational choice perspective with the capability approach and the accommodation model of childcare choices. Particular attention is paid to variations across families with varying levels of education, income, migration background, and partnership status. After reviewing existing evidence on the effects of regional variations in childcare provision on social inequalities in take-up, maternal employment and workfamily balance, and on some of the mechanisms, the chapter concludes by pointing to research gaps and new frontiers of regional family policy analysis. It outlines the current challenges and new demands for data collection and linkages necessary to realize the full potential of regional family policy analysis. 
The Netherlands provides extensive and flexible childcare provision to support young parents. Even though the Netherlands is not a federal state, unlike the United States and Germany covered in previous chapters, the national-level policy on childcare isn't evenly distributed, and provision is better for some than for others. Childcare, like education and healthcare, is centered around physical infrastructure and this ensures that provision and access are structured by traditional geographies of inequality. In Chapter 20, Tom Emery examines detailed data on childcare in the Netherlands from a range of data sources to explore social gradients in access to childcare at the very local level. Survey respondents are geocoded and are linked to the Landelijk Register Kinderopvang en Peuterspeelzalen (Register for Childcare and Toddler Groups). In linking this data, three often neglected dimensions of childcare provision are captured. First, at the most basic level the geographic proximity of childcare services is captured (i.e., distance to nearest provider). Second, the availability of choice is measured (i.e., number of providers within $2 \mathrm{kms}$ ). Third, the diversity of options is measured (i.e., the ratio of different types of providers). The richness of the geographical registry data and the survey data allow for a detailed assessment of childcare provision at the regional and subregional level and the extent to which it is associated with wider socioeconomic cleavages. The findings illustrate the strong association between the geographical availability of childcare and the ability of women to work longer hours. However, more informal forms of childcare support such as childminders or family networks are not directly associated with a return to employment. Specifically, these results enable the identification of specific subregions where geographical challenges in the provision of childcare persist and an overview of subnational initiatives to address these childcare deserts. Precise estimates of geospatial contexts translate directly into more precise policy interventions and a shorter line between research and policymakers.

\section{Organizations}

A vast literature exists on how organizations support their workers. Organizational norms and practices such as opportunities for part-time work, flexible working hours, overtime regulation, employer-provided childcare facilities, and telework options are now known to affect the well-being of workers (Lewis, Anderson, Lyonette, Payne, \& Wood, 2017). More recently, crossovers started to emerge between the literature on what organizations do and the literature on what states bring about with respect to work and family, and their interaction (Abendroth, Van der Lippe, \& Maas, 2012). This has led, for instance, to the important insight that organizations compensate for the 
absence of national-level policies to combine work and family, but only to a limited extent (Den Dulk et al., 2012).

The motivation to study the workplace context is that existing research shows there is often a gap between policy and practice, that is, workers refrain from taking advantage of existing national and/or workplace policies. The fact that workers do not always utilize policies, even when they need to, suggests that there are constraints which influence their sense of entitlements and claims to existing policies. Hence, to fully understand how work-family policies play out at the workplace we also need to address how arrangements and policies are mediated, translated, and implemented within organizations. It is at the workplace and work-organizational level that formal work-family policies are converted into entitlements and claims, where requests are granted or denied. This can have profound consequences for social inequality between workers within the same company, or between workers in different companies. Heejung Chung (Chapter 21) develops the argument that not only do organizations define the 'final availability' workers actually have toward various family policy arrangements, organizations may also provide various additional arrangements through occupational policies which are not set out in the national-level agreements that are crucial in addressing reconciliation needs of workers. This chapter empirically examines what types of arrangements are provided at the organizational level to address work-family demands of workers. It further provides a synthesis of the literature on why organizations provide such policies as well as to whom it is provided, which is linked to the possible outcomes of organization-level family-friendly policies.

With the importance of organizational family policy and practice clearly demonstrated, a question of central importance is who benefits from these policies. This pertains not only to which organizations provide such policies, but also which workers within organizations can access them. This is examined by Katia Begall and Tanja van der Lippe (Chapter 22), using uniquely rich, cross-national data with a multilevel design. Their chapter focuses exclusively on the question to what extent access to and use of organizational policies related to work-life balance, flexibility, training, and health is stratified by education. The argument is that work-family research has paid little attention to differences by education above and beyond the differences which can be expected based on occupational and job differences. Whether lowskilled (measured by education) workers are able to make use of these policies and in how far they can benefit as much from them as higher-skilled workers in organizations are therefore central questions in this chapter. Advocating a multilevel perspective, the chapter analyses how the availability, use, and 
consequences of work-family policies differ by education incorporating a wide range of indicators on the individual and organization level.

Despite organizations increasingly operating in multiple countries, there has been limited discussion among researchers regarding the roles and responsibilities of human resources (HR) managers in multinational enterprises and to work-life management in the global context. Anne Bardoel (Chapter 23) discusses and analyzes multinational enterprises (MNEs), where managing work-life issues presents a number of challenges for HR departments because of the complexity of implementing policies that require sensitivity to local issues such as cultural traditions and legislation. A tension-centered approach to analyzing these complexities in MNEs with a particular focus on work-life management and strategy development provides insights into constraints and challenges to organizations operating globally. There is evidence that tensions often exist in MNEs between corporate/global HR, local HR, and operational line managers involved in the implementation of work-life policies and practices. The promise of the tension-centered approach is that it provides insight into the ways these tensions are resolved in practice, and that it can point toward strategies to improve relevant practices.

\section{The Next Decade of Research}

This Handbook is testimony to the multitude of methods, research traditions, and data sources that have been deployed to study family policies and their outcomes. While early attempts to cross-national family policy research had to use fragmented data, recent studies have a whole range of cross-country comparable survey data on income, employment, and living conditions at their disposal, alongside publicly accessible databases with policy indicators in the fields of childcare, child benefits, leave policies, and fiscal policies. An increasing number of studies rely on more technically advanced methods, such as microsimulation studies, quasi-experiments, or studies based on model family types to examine the particular design of family policies. Still, scientific progress in terms of understanding the outcomes of family policies at different levels is often hampered by a lack of high-quality data. In their chapter, Sirén, Doctrinal, Van Lancker, and Nieuwenhuis (Chapter 24) focus on the salient issue of childcare. Arguably it is the policy area which gets the most attention in today's discussions on family policy, while the data and indicators available to study it are least developed. In their chapter, they discuss the current availability of comparative data sources and their limitations, and spell out what kind of data investment is needed to push forward 
the childcare research agenda in particular, bearing broader relevance for data issues in family policy research in general. In particular, they argue for the need to engage in a research agenda that integrates family policies, including social care services, as essential components of social citizenship.

In Chapter 25, Nieuwenhuis develops a research agenda for examining family policy outcomes with respect to vertical economic inequality between households, arguing that family policies have wrongly been neglected as a determinant of vertical economic inequality. Three questions are central to this research agenda: who uses family policy, to what income effect, and with whom do they live? Family policies have been linked to women's employment and earnings, and to lower vertical income inequality. Yet, the literature also makes abundantly clear that family policies come with trade-offs along the lines of gender and class, as well as Matthew effects. These mechanisms need to be better understood to integrate family policy in analyses of - and recommendation against-high and rising inequality. The challenge ahead is to understand what (combination of) family policies may be inclusive to a wide range of families across the full width of the income distribution.

In the final chapter 26, Van Lancker and Nieuwenhuis highlight five major societal challenges for the future outlook and outcomes of family policies, and reflect on what the handbook teaches us about how to effectively address these challenges. The challenges pertain to the (1) levels of policy implementation, and in particular globalization and decentralization, (2) austerity and marketization, (3) economic inequality, (4) changing family relations, and (5) welfare states adapting to women's empowered roles. The chapter concludes with a reflection on what we learned, and are yet to learn, regarding the role played by family policies in cushioning economic, social, and health shocks of various kinds. How well current theories and empirical findings help us understand to what extent family policies support families during extraordinary times remains a challenge for the next decade of research.

\section{References}

Abendroth, A. K., Van der Lippe, T., \& Maas, I. (2012). Social support and the working hours of employed mothers in Europe: The relevance of the state, the workplace, and the family. Social Science Research, 41(3), 581-597.

Béland, D., \& Lecours, A. (2005). The politics of territorial solidarity: Nationalism and social policy reform in Canada, the United Kingdom, and Belgium. Comparative Political Studies, 38(6), 676-703.

Boushey, H. (2016). Finding time. Cambridge, MA: Harvard University Press. 
Bradshaw, J., \& Finch, N. (2002). A comparison of child benefit packages in 22 countries. Corporate Document Services.

Den Dulk, L., Peters, P., \& Poutsma, E. (2012). Variations in adoption of workplace work-family arrangements in Europe: The influence of welfare-state regime and organizational characteristics. The International Journal of Human Resource Management, 23(13), 2785-2808.

Engster, D., \& Stensöta, H. O. (2011). Do family policy regimes matter for children's well-being? Social Politics: International Studies in Gender, State \& Society, 18(1), 82-124.

Esping-Andersen, G. (1990). The three worlds of welfare capitalism. Princeton, NJ: Princeton University Press.

Gauthier, A. H. (1996). The state and the family: A comparative analysis of family policies in industrialized countries. New York and Oxford: Oxford University Press.

Gauthier, A. H. (2002). Family policies in industrialized countries: Is there convergence? Population, 57(3), 447-474.

Heymann, J., \& Earle, A. (2009). Raising the global floor: Dismantling the myth that we can't afford good working conditions for everyone. Stanford Politics and Policy.

Kahn, A., \& Kamerman, S. B. (1978). Family policy: Government and families in fourteen countries. New York: Columbia University Press.

Kamerman, S. B. (2006). A global history of early childhood education and care. 2007/ED/EFA/MRT/PI/19. United Nations Educational, Scientific and Cultural Organization.

Korpi, W. (2000). Faces of inequality: Gender, class, and patterns of inequalities in different types of welfare states. Social Politics: International Studies in Gender, State \& Society, 7(2), 127-191.

Korpi, W., Ferrarini, T., \& Englund, S. (2013). Women's opportunities under different family policy constellations: gender, class, and inequality tradeoffs in Western Countries re-examined. Social Politics: International Studies in Gender, State \& Society, 20(1), 1-40. https://doi.org/10.1093/sp/jxs028.

Lister, R. (1994). "She has other duties": Women, citizenship and social security. In S. Baldwin \& J. Falkingham (Eds.), Social security and social change: New challenges to the Beveridge Model (pp. 31-44). Hempel Hempstead: Harvester Wheatsheaf.

Levels, M., Need, A., Nieuwenhuis, R., Sluiter, R., \& Ultee, W. (2012). Unintended pregnancy and induced abortion in the Netherlands 1954-2002. European Sociological Review, 28(3), 301-318. https://doi.org/10.1093/esr/jcq065.

Lewis, J. (1992). Gender and the development of welfare regimes. Journal of European Social Policy, 2(3), 159-173.

Lewis, S., Anderson, D., Lyonette, C., Payne, N., \& Wood, S. (2017). Public sector austerity cuts in Britain and the changing discourse of work-life balance. Work, Employment \& Society, 31(4), 586-604.

Mandel, H. (2012). Winners and losers: The consequences of welfare state policies for gender wage inequality. European Sociological Review, 28(2), 241-262. 
McLaughlin, E., \& Glendinning, C. (1994). Paying for care in Europe: Is there a feminist approach? In L. Hantrais \& S. Mangen (Eds.), Family policy and the welfare of women, cross-national research papers (pp. 52-69). Loughborough: Cross-National Research Group, European Research Centre, Loughborough University of Technology.

Merton, R. K. (1936). The unanticipated consequences of purposive social action. American Sociological Review, 1(6), 894-904.

Montanari, I. (2000). From family wage to marriage subsidy and child benefits: Controversy and consensus in the development of family support. Journal of European Social Policy, 10(4), 307-333.

Nieuwenhuis, R., \& Maldonado, L. C. (Eds.). (2018). The triple bind of singleparent families: Resources, employment and policies to improve wellbeing. Bristol: Policy Press.

Nieuwenhuis, R., Need, A., \& Van Der Kolk, H. (2017). Is there such a thing as too long childcare leave? International Journal of Sociology and Social Policy, 37(1/2), 2-15.

Orloff, A. S. (2009). Gendering the comparative analysis of welfare states: An unfinished agenda. Sociological Theory, 27(3), 317-343.

Pavolini, E., \& Van Lancker, W. (2018). The Matthew effect in childcare use: A matter of policies or preferences? Journal of European Public Policy, 25(6), 878893.

Pettit, B., \& Hook, J. L. (2009). Gendered tradeoffs: Women, family, and workplace inequality in twenty-one countries. New York: Russell Sage Foundation.

Ranci, C., \& Pavolini, E. (Eds.). (2013). Reforms in long-term care policies in Europe: Investigating institutional change and social impacts. Springer.

Robila, M. (2012). International perspectives on family policies. Journal of Child and Family Studies, 21, 1-3.

Thévenon, O. (2011). Family policies in OECD countries: A comparative analysis. Population and Development Review, 37(1), 57-87.

Thévenon, O., \& Luci, A. (2012). Reconciling work, family and child outcomes: What implications for family support policies? Population Research and Policy Review, 31(6), 855-882.

Van der Lippe, T., \& Van Dijk, L. (2001). Comparative Research on women's employment. Annual Review of Sociology, 28(1), 221-241. https://doi.org/10. 1146/annurev.soc.28.110601.140833.

Van der Lippe, T., \& Van Dijk, L. (2002). Comparative research on women's employment. Annual Review of Sociology, 28(1), 221-241.

Van Lancker, W., \& Ghysels, J. (2016). Explaining patterns of inequality in childcare service use across 31 developed economies: A welfare state perspective. International Journal of Comparative Sociology, 57(5), 310-337.

Van Lancker, W., \& Van Mechelen, N. (2015). Universalism under siege? Exploring the association between targeting, child benefits and child poverty across 26 countries. Social Science Research, 5, 60-75. 
Open Access This chapter is licensed under the terms of the Creative Commons Attribution 4.0 International License (http://creativecommons.org/licenses/by/4.0/), which permits use, sharing, adaptation, distribution and reproduction in any medium or format, as long as you give appropriate credit to the original author(s) and the source, provide a link to the Creative Commons licence and indicate if changes were made.

The images or other third party material in this chapter are included in the chapter's Creative Commons licence, unless indicated otherwise in a credit line to the material. If material is not included in the chapter's Creative Commons licence and your intended use is not permitted by statutory regulation or exceeds the permitted use, you will need to obtain permission directly from the copyright holder. 